\title{
POSSIBILITIES OF MORE EFFICIENT USE OF SIMULATION TOOLS IN ENTERPRISE LOGISTICS
}

\author{
Matúš Hegedüš', Gabriel Fedorko', Matúš Beluško', Martina Hlatká2, \\ Pavel Fábera ${ }^{3}$, Hana Neradilová ${ }^{4}$
}

${ }^{1}$ Technical University of Košice, Letná 9, 04200 Košice, Slovak Republic, e-mail: matus.hegedus@tuke.sk; gabriel.fedorko@tuke.sk; matus.belusko@tuke.sk

2 Institute of Technology and Business in Česke Budějovice, Okružní 517/10, 37001 české Budějovice, Czech Republic, e-mail: hlatka@mail.vstecb.cz;

3 GW Train Regio a.s. , U stanice 827/9, 40003 Ústi nad Labem, Czech Republic, e-mail: pavel.fabera@gwtr.cz

4 College of Logistics in Přerov, Palackého 1381/25, 75002 Přerov, Czech Republic, e-mail: hana.neradilova@ vslg.cz

Received: 2017.10 .10

Accepted: 2017.11.01

Published: 2017.12.05

\begin{abstract}
Computer simulation, as a powerful scientific and engineering tool, is increasingly used to solve a wide range of issues within the enterprise logistics processes. This trend is mainly due to the fact that the computer simulation method offers a whole range of benefits for enterprise logistics e.g. saving time, space and finance. The use of computer simulation in logistics, however, still has certain limitations that handicap it and do not allow it to be more operationally exploited. The main reason is that the creation of models of different logistics processes is exacting on the skills and knowledge in this area. The factors as the difficulty of creating new and modifying existing models or repeating simulation experiments complicate the more frequent application of computer simulation models in logistics. For this reason, it is necessary to look for a way to simplify and make the issue available to a larger circle of users.
\end{abstract}

Keywords: simulation, logistics, software, efficiency, modelling.

\section{INTRODUCTION}

Currently, in the context of enterprise logistics, computer simulation is one of the dominant tools for obtaining, evaluating a wide range of information and supporting decision-making [1]. This is mainly because its application brings enormous potential. For example, by using this method, logistics staff can analyze selected business logistics processes to the smallest detail, verify the impact of individual changes and measures on a complex logistics system or its component parts [2].

The use of the computer simulation method incorporate logistics has gradually shifted from the strategic level of the enterprise to the tactical and is already slowly becoming familiar at the operational level at present. It is possible to opti- mize production plans, plan the receipt of goods in warehouses or analyze the performance of individual logistics processes using this tool [3].

In the field of logistics, there are used mainly discrete simulation models in connection with computer simulation [4]. Discrete-oriented simulation is used primarily for planning, reviewing and monitoring individual processes [5]. The synchronization of individual production processes in terms of supply is another suitable area for applying this method [6]. Today, the use of the computer logic simulation method in the field of enterprise logistics is constantly evolving and utilizing various new trends and approaches in the field of information technologies, such as cloud [7].

As mentioned above, we can efficiently use simulation models for transport and supply logistics planning across different types of techno- 


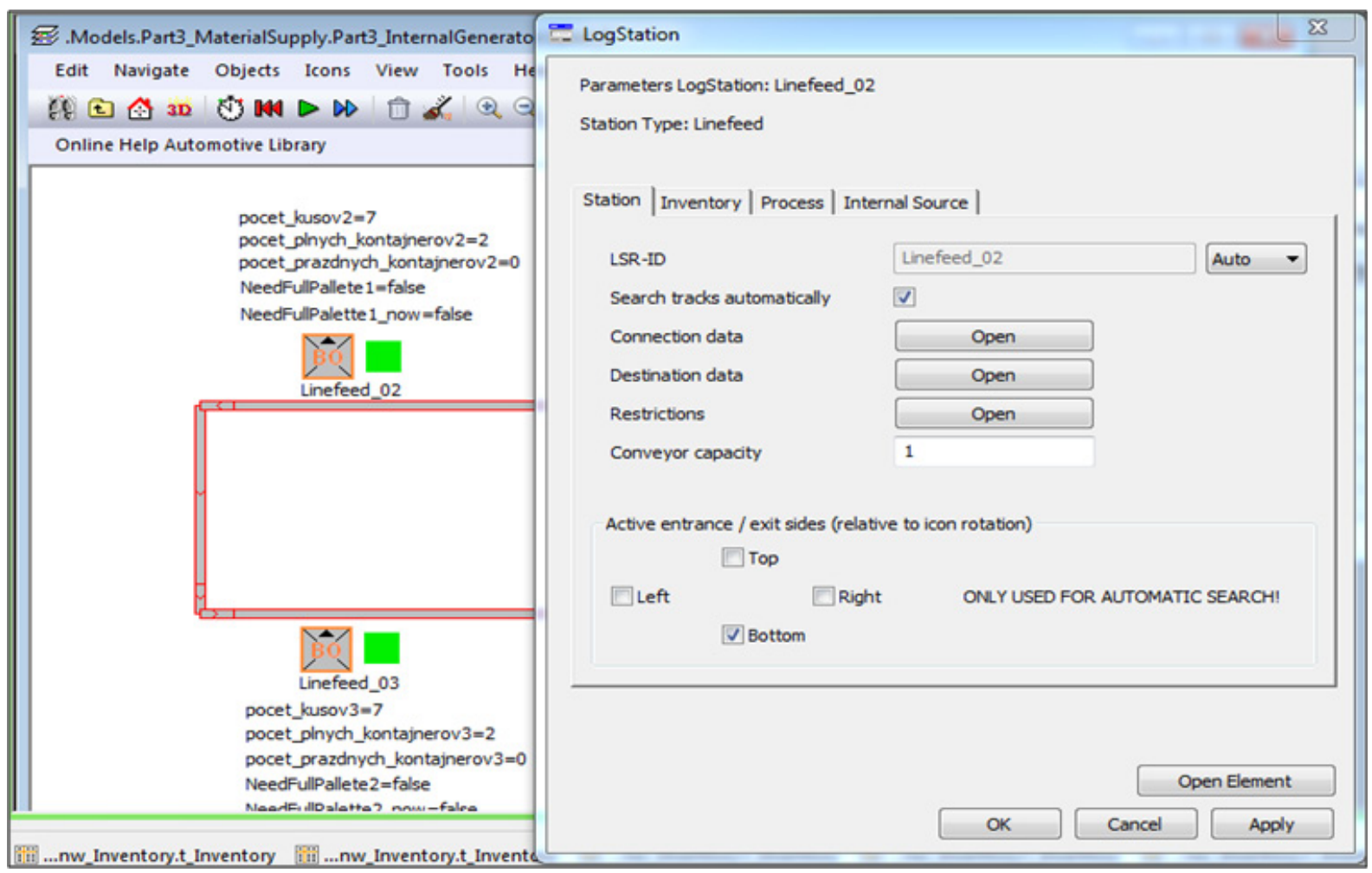

Fig. 1. The LogStation block

logical processes [8]. These are often transport systems which, for example, can be used for the operation of logistic trains. Dias et al. [9] describe the use of computer simulation for logistics trainers and their operation within the Milk Run system. However, we can meet the requirement for rapid modification and variation to create simulation models of transport processes and other processes enterprise logistics $[10,11,12]$. However, this can mean a significant problem that is related to the development of simulation programs itself and the development of a computer simulation method.

\section{PROBLEMS ASSOCIATED WITH CREATING SIMULATION MODELS IN ENTERPRISE LOGISTICS}

The problem of creating simulation models and realization of simulation experiments in the area of enterprise logistics has its own specifics $[13,14]$. In the beginnings of using the simulation method in logistics processes, the first problems have already begun, especially when operating simulation programs $[15,16]$.

The first simulation tools put into practice were based on the principle of machine programming. There were several drawbacks in the simu- lation. If anyone wanted to simulate any logistical process, he had to know to control the programming language. There were several drawbacks in the simulation. One is the need to control the programming language to simulate any logistical process. In other words, they created a whole simulation based on the information they provided, but they understood the issue of enterprise logistics only minimally.

However, there was another immediate disadvantage for businesses. Because the employment of programmers was inefficient in terms of the use of their work capacities. Because they worked the role by programming the simulation, their further use was needed only when creating another model.

This has led to individual departments of enterprise logistics having begun to design the requirements of developers to create simulation programs that can be handled by a logistics specialist after training and not just a programmer. These requirements have gradually led to the emergence of a new generation of simulation languages. But, other problems have come to the scene with the onset of a new generation of simulation tools. These include, for example, the imperfections of libraries and the minimal versatility of individual simula- 


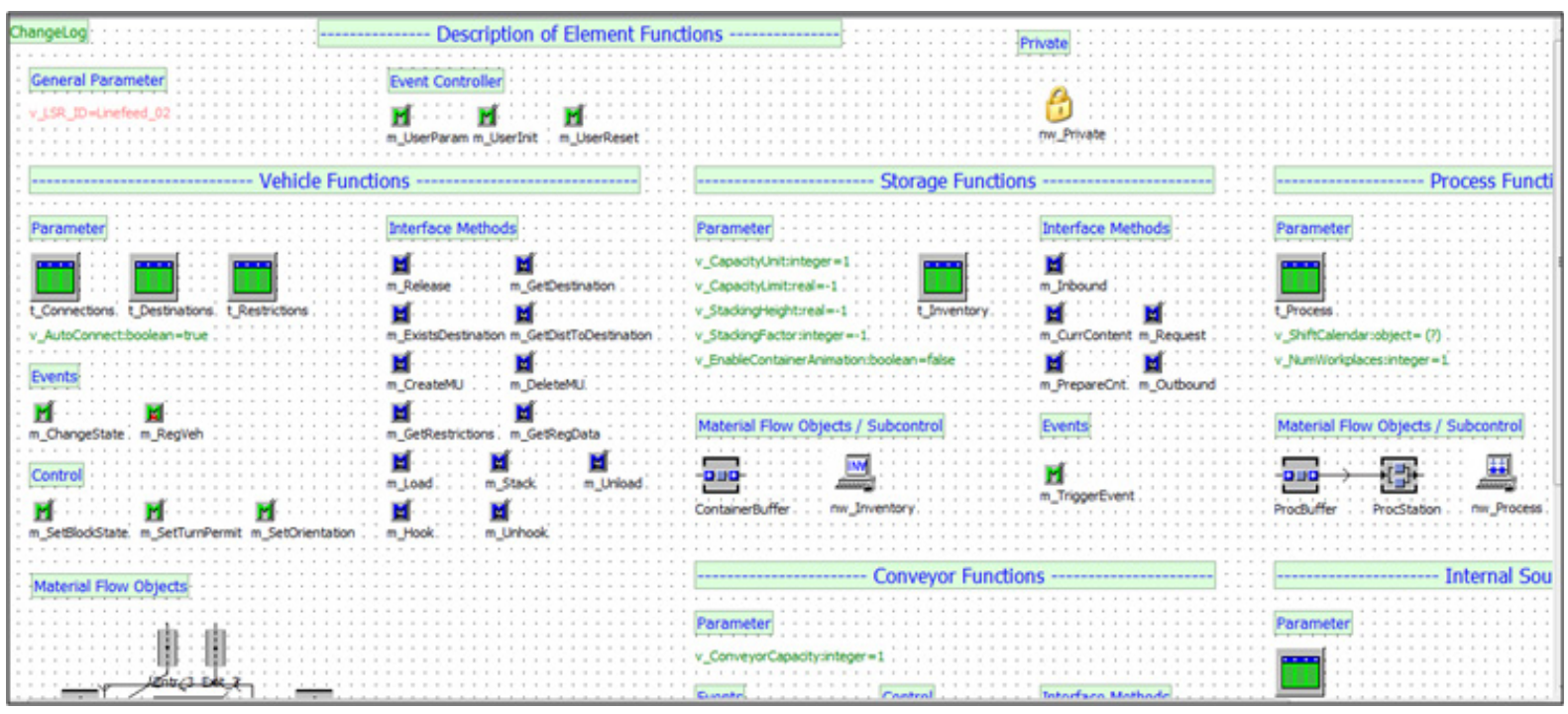

Fig. 2. The content of the LogStation block

tion programs. Most companies have demanded universal software (which they could use in multiple directions of their business) from developers. These requirements culminated in the fact that we currently had simulation programs on the market that was provided by the modular modeling system.

The new generation of simulation systems contains several types of building blocks in the form of blocks and commands from which it is possible to create the required simulation model very quickly and conveniently. Thus, simulation programs resemble a kit whose individual parts can be combined. Today, many of these simulation programs are also available with the option of extending the system version, allowing the user to create custom modular elements. One of the results of such efforts (for example in the au- tomotive industry) is to create a portfolio of VDA logistics libraries that are designed for use in the Tecnomatix Plant Simulation software tool.

\section{USING VDA LI BRARIES TO SIMULATE BUSINESS LOGISTICS PROCESSES}

The concept of VDA, which originates in the German engineering industry, can be defined as a standard quality management system. In this case, these are VDA libraries that serve to simplify the simulation model creation and to simplify the manipulation of the model.

At present, progress in simulation modeling is at a level that a trained person can handle manipulation with a selected simulation model, but it does not apply when creating a model. Such a breakthrough was achieved due to the

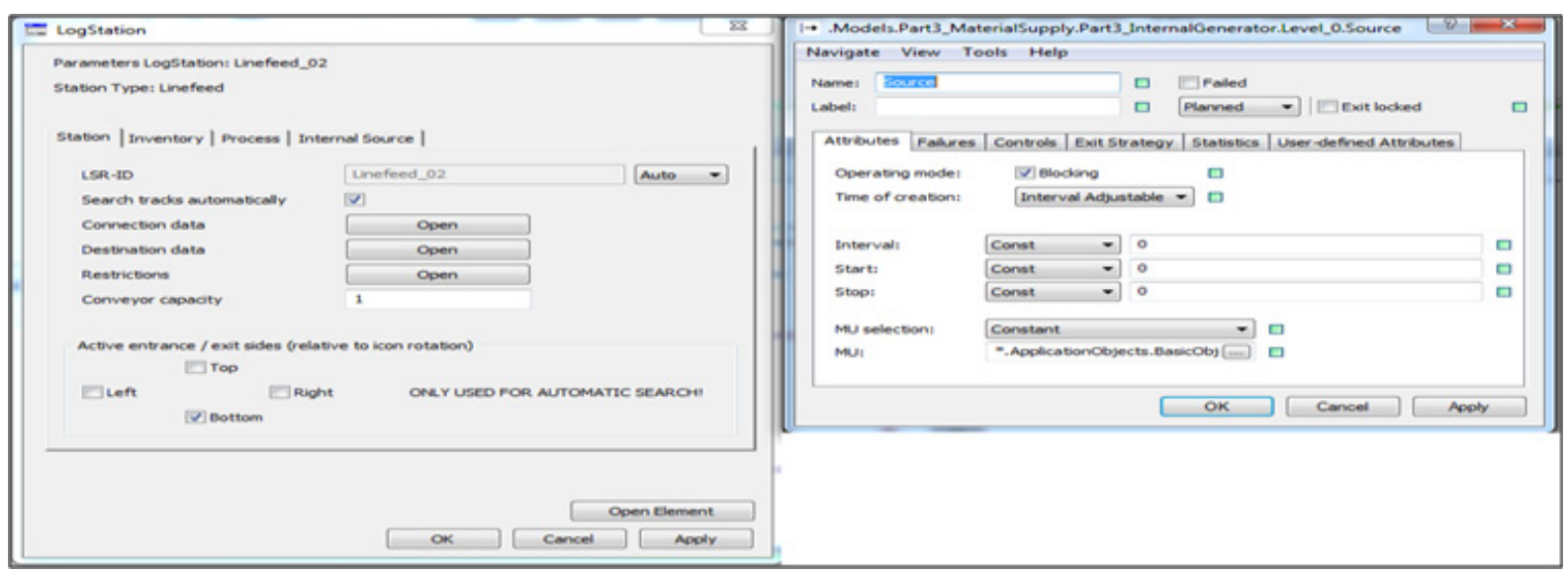

Fig. 3. Comparison of Log Station and Source blocks 


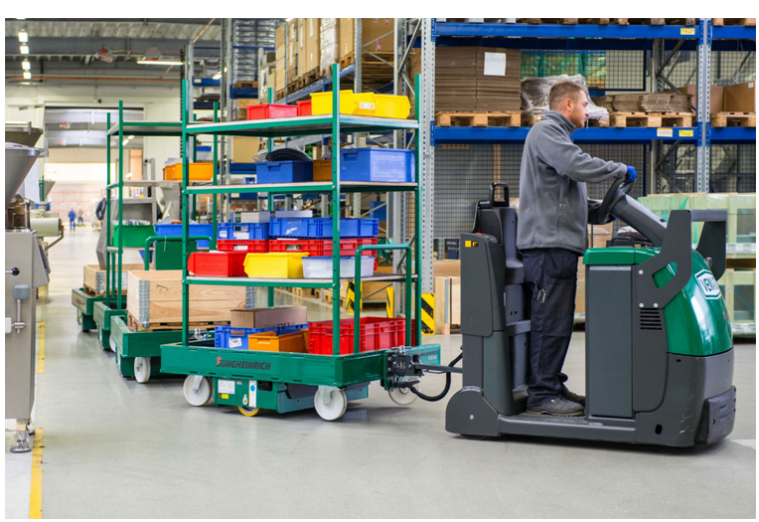

Fig. 4. Demonstration of logistics train [17]

use of pre-defined libraries. These libraries are made up of special blocks that have multiple blocks (several hundred) integrated from the basic libraries. Therefore, we only need a small number of blocks from a pre-created library to create a more complex simulation model. The great advantage is simple manipulation and creation of simulation models. However, every advantage has its disadvantage. The disadvantage is that this kind of libraries is not universal and can only be used when creating models in the selected area.

The creation of VDA libraries is closely related to its use. It's a never-ending story in which library user comments are the main information for programmers. The more complex the process, the more it is necessary to modify the individual blocks of the library for the simple creation of the model itself.

The Figure 1 shows the selected LogStation block from the VDA library used in the automotive industry. The advantage of this block is that we do not have to connect it to other blocks of one another. The only action (which is done for the connection) is the determination from which side the block will be automatically fed to the other blocks. There are four options to choose from: top, bottom, left, right.

Another advantage is easier manipulation with block settings than the basic block in the classic version of the simulation program. Work-

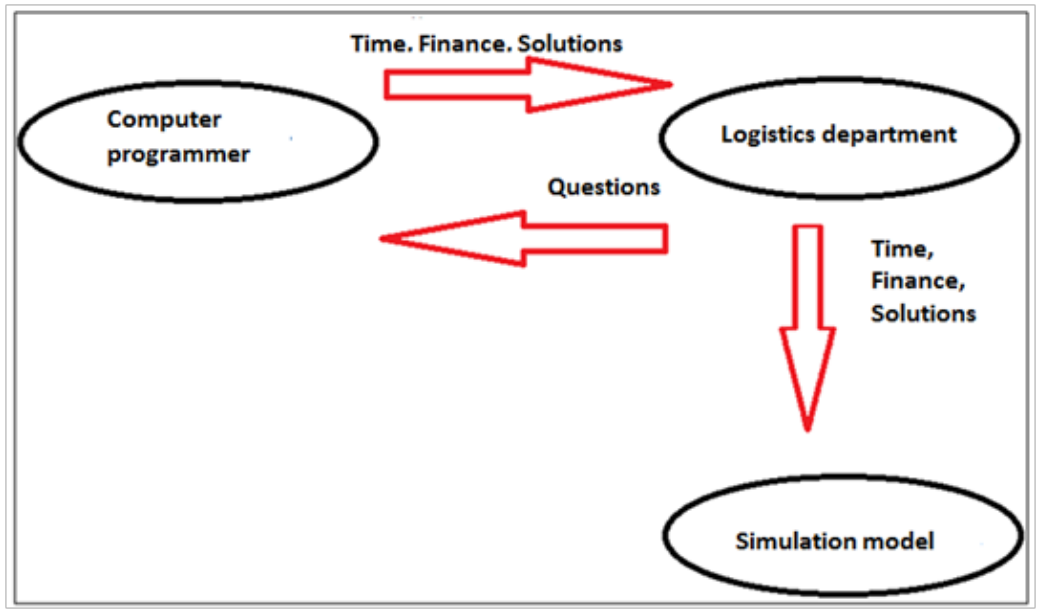

Fig. 5. The course of the proposed process of creating a simulation model

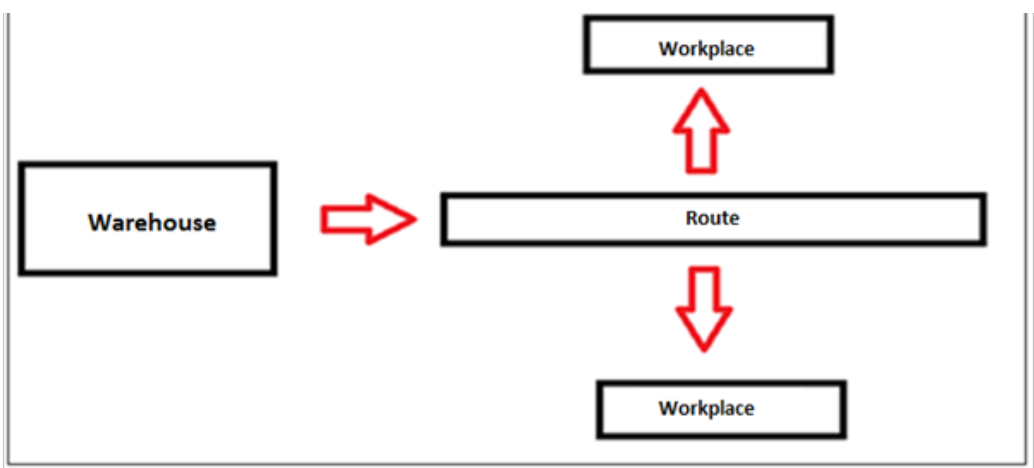

Fig. 6. Part of a simulated process scheme 


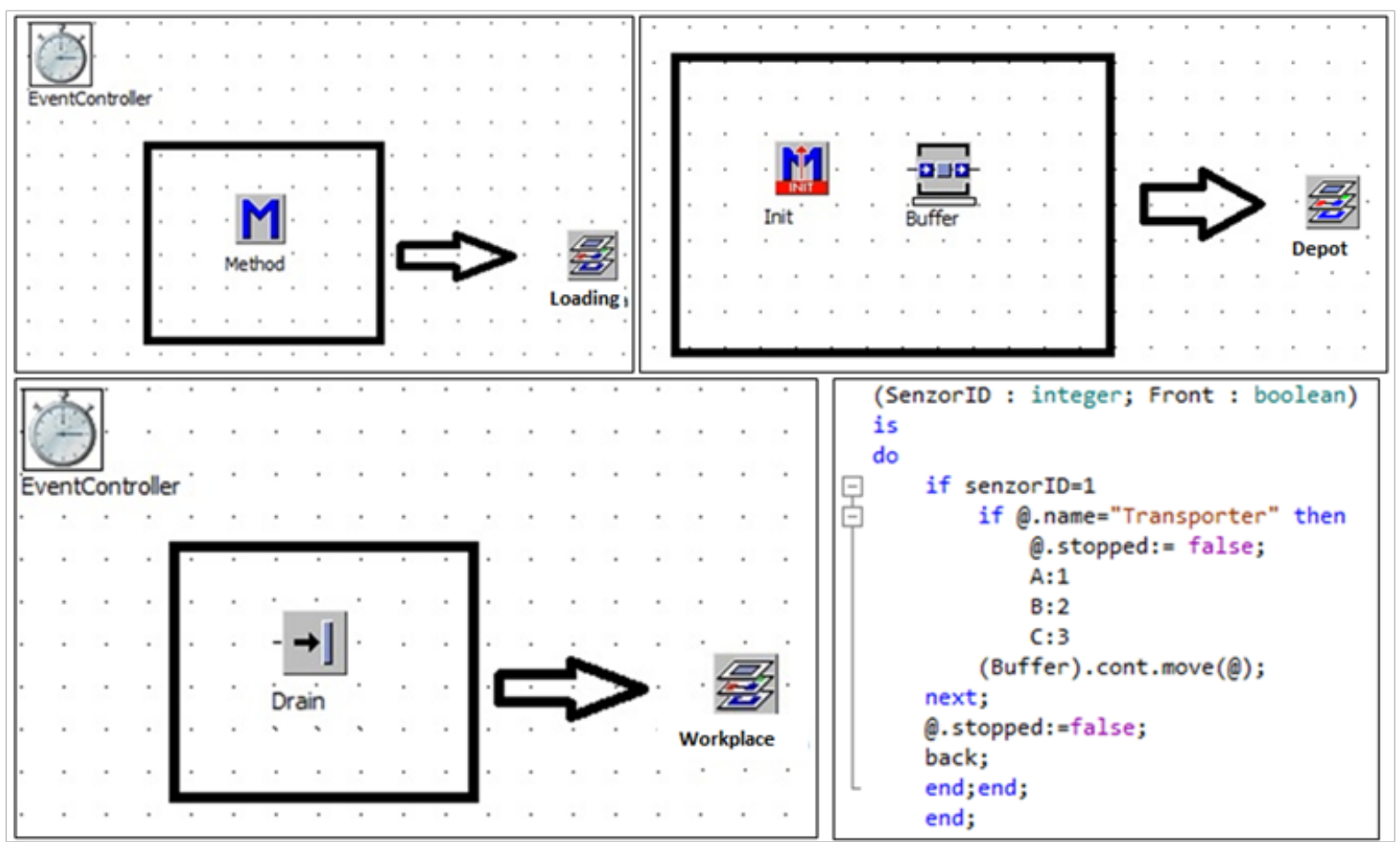

Fig. 7. Structure of blocks created and demonstration of the supplementary programming method

ing with the dialog box created by the block is easier than with the block from the base library.

A closer look at each of the predefined blocks shows that one block consists of multiple blocks of the base library. In Figure 2, there is a preview of the detailed structure and composition of the LogStation block.

The Figure 3 shows a block comparison from a VDA library and a block from a base library. On the left, there is the LogStation block from the VDA library, which is made up of sev- eral blocks from the base library and has easier control. The reason is to simplify manipulation, which means that the trained person can handle the logistics process. On the right, there is a Source block that belongs to the base library blocks. It can be part of a block from the VDA library, too. At first glance, there is the difference and complexity of setting the block properties. The basic functionality of both blocks is the same, which is to generate input requirements into the simulation model.

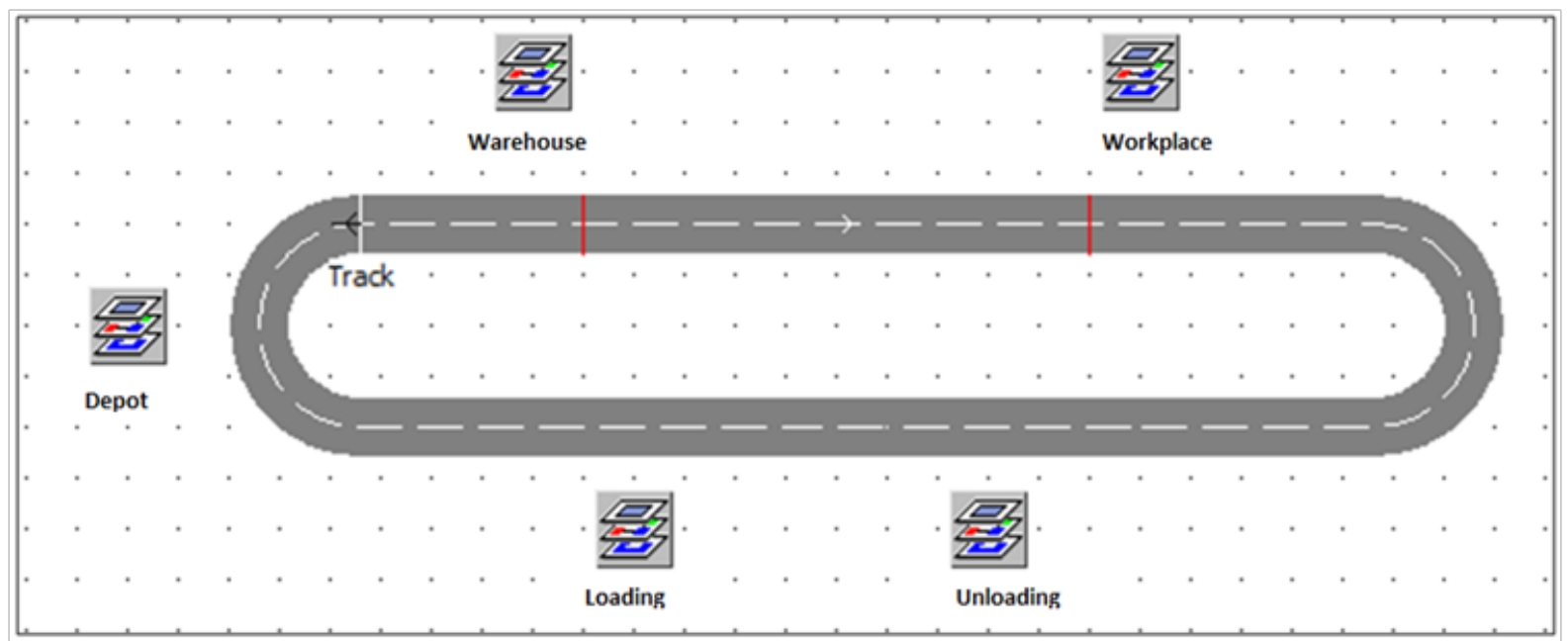

Fig. 8. Example of a simple simulation model 


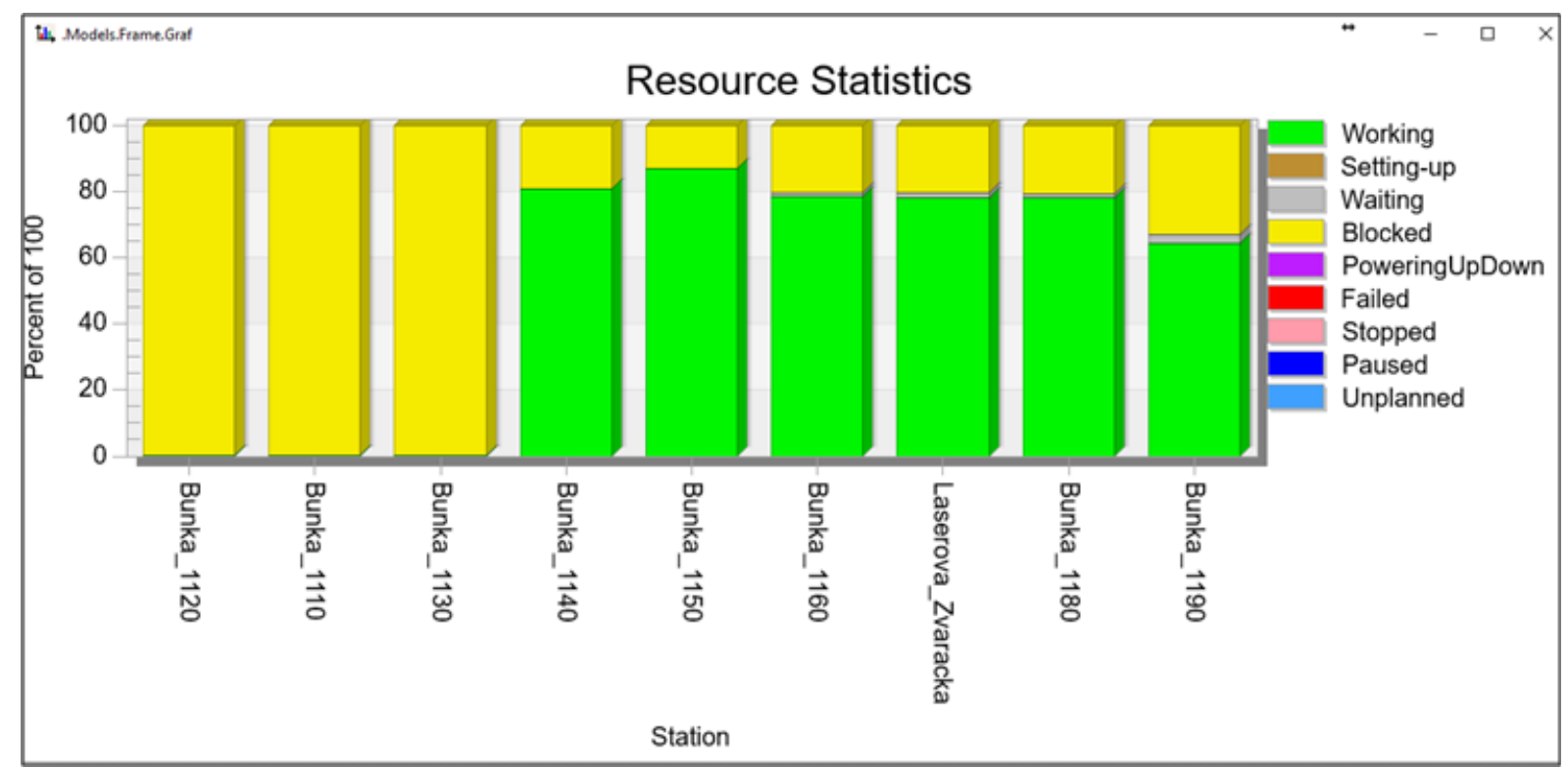

Fig. 9. Demonstration of workload visualization

\section{DESIGN OF VARIABLE SYSTEM MODELLING THE SUPPLY PROCESSBY LOGISTIC TRAINS}

The requirements for the rapid creation of simulation models and their operative modification occur very often. However, it is very difficult to provide the desired speed of creation. The necessary specialist for creating a simulation model needs a certain amount of time to study the background and to develop a simulation model. It is similar even when the need for subsequent modifications and adjustments simulation model.
We can meet this problem, for example, the creation process simulation model of supply logistics train (Figure 4), the transport routes need to be changed at irregular intervals for various reasons. When creating this model, it would be possible to use VDA libraries and Tecnomatix Plant Simulation. However, this would be a very time-consuming and financial process. Also, if its modifications and modifications are sufficient, e.g. allocation of individual workplaces, this would have to be done with the original creator of the simulation model in most cases, which would re-complicate and prolong the whole process.

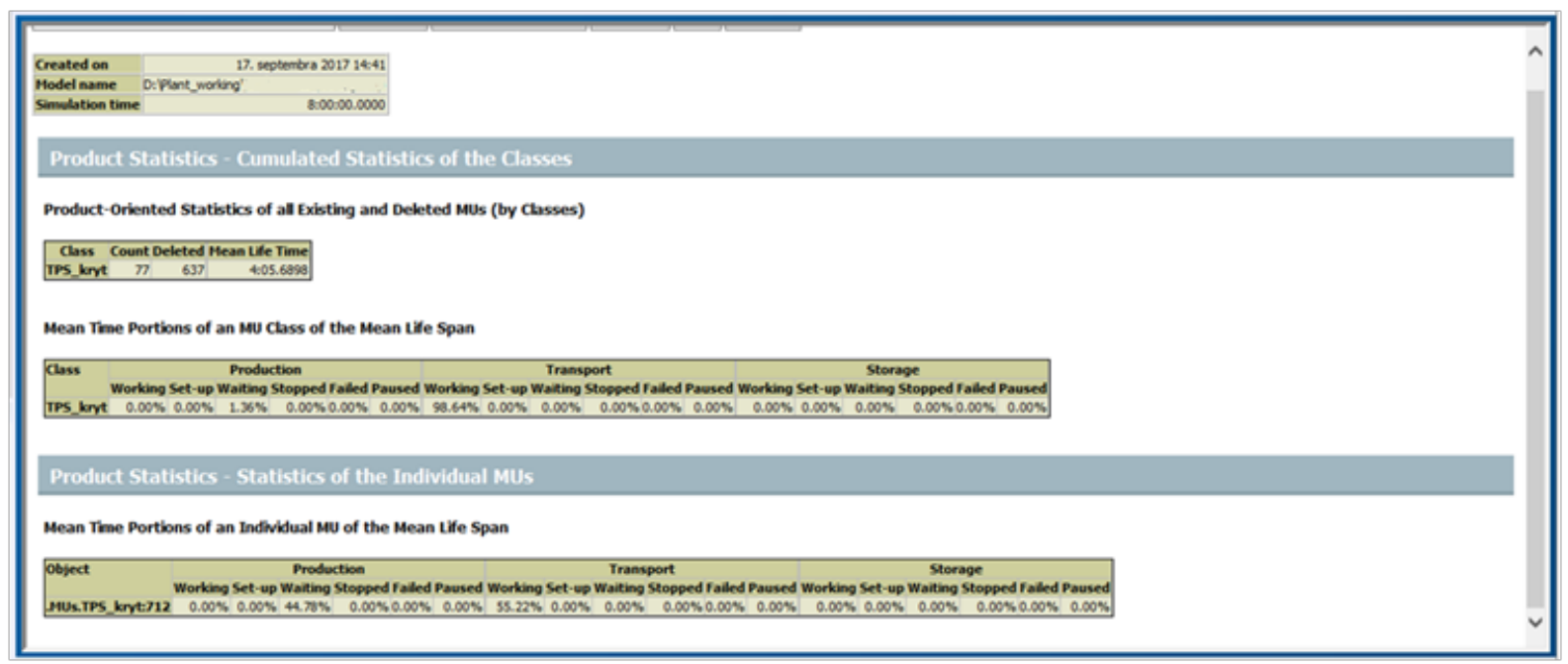

Fig. 10. Example of statistical information obtained from the simulation experiment 
One of the possible solutions is shown in Figure 5. This is the process of creating a simulation model in which we use a suitable simulation program, Tecnomatox Plant Simulation and help in the initial phase of a programmer's specialist. Custom Block Library (which will contain clearly defined inputs and outputs) will be created using it and based on the requirements.

\section{SIMULATION MODEL OF THE SUPPLY PROCESS BY LOGISTIC TRAINS}

In the library, the user has created selection blocks (according to the schematic part of Figure 6) that depict the store, workplace, and traffic communication. When working with this created library, we work only with the blocks it contains. A trained logistics worker can carry out the construction of a model structure. Model creation consists only in selecting the required blocks, adjusting their parameters and placing them in accordance with the relevant layout. The way the model is created is based on the kit principle. A logistics worker composes individual workplaces according to the technological process and starts the simulation. The wide range of processed information, between the logistics department itself and the programmer, precedes this process.

Individual blocks are created in such a way that their connection is realized automatically and each block can automatically identify its position. This important feature was created using the addon programming method (Figure 7, Figure 8).

The principle of the supplementary programming method is based on the recording of commands that ensure the implementation of the selected activities by the SimTalk programming language.

\section{USING THE SIMULATION MODEL}

The concept of creating the simulation model is very effective and brings simplification of the work associated with the use of computer simulation. It was possible to create a highly sensitive and variable simulation model of the supply process through logistic trains by its application. The Simulation Model allows us to implement an unlimited number of predefined workstations. Such

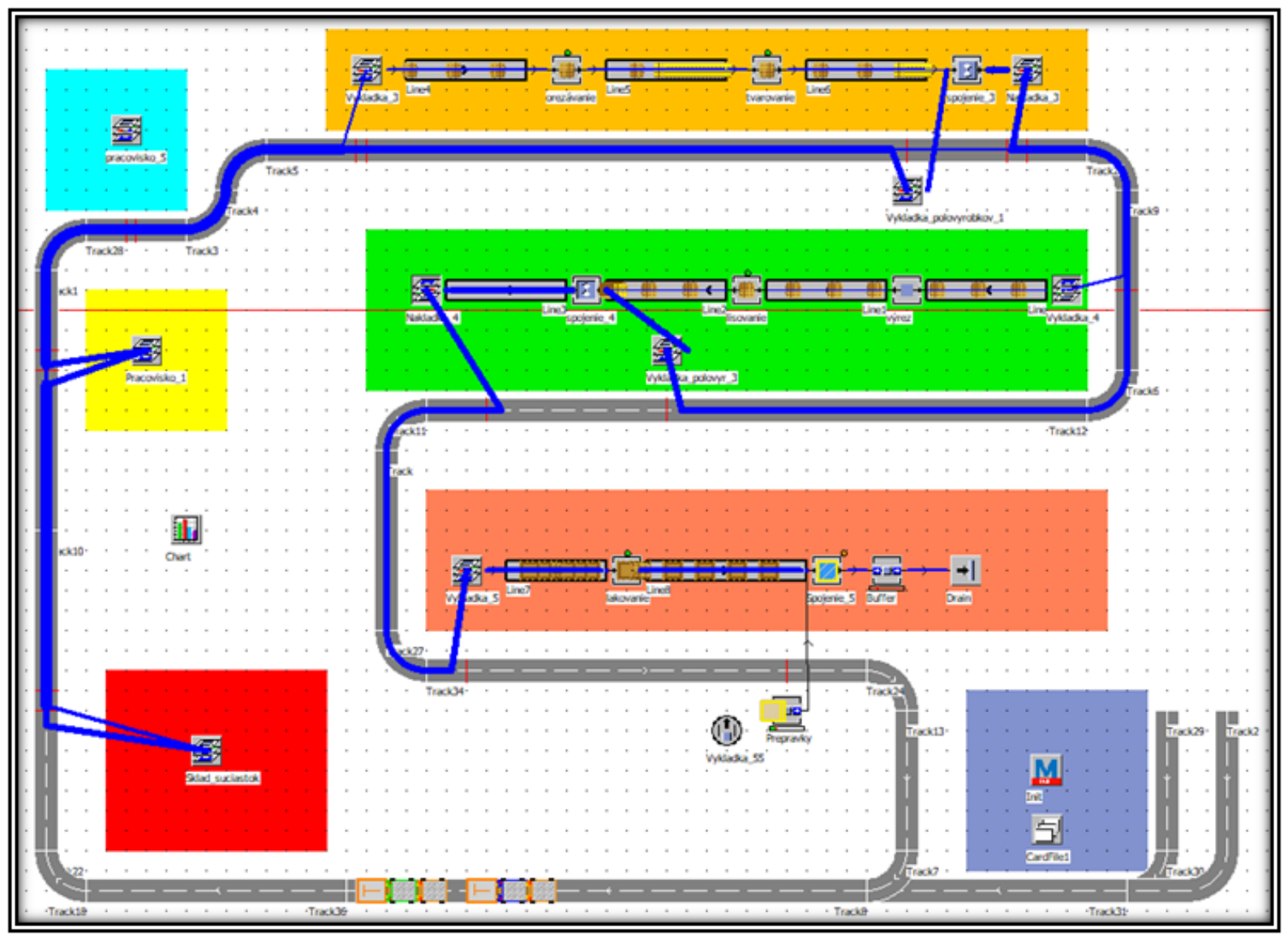

Fig. 11. Labelling of the material flow obtained by the simulation experiment 
a structured simulation model no longer requires the use of specialists to carry out further modifications. Conversely, specialists of enterprise's logistics can work with it after a brief training.

The simulation model can be used for verification of individual variants keeping traffic routes. The simulation model may be used for verification of individual variants solutions of transport routes. Furthermore, all selected data can be used as a support tool for decision-making and planning processes (Figure 9). Realization of individual simulation experiments (specifically their preparation) takes place in the minimum possible time interfaces. There are minimized financial costs that would be much higher in the classical process due to the constant use of external simulation model makers.

Also, the simulation model allows us to verify the material distribution plans created in individual workplaces. In case of shortcomings, we can quickly implement additional corrections and adjustments. The information provided by the system is practically unlimited (Figure 10). Their disadvantage is only that the information requirements need to be determined in advance when designing individual modular blocks, or their incorporation is possible in a later phase of use, but again after the intervention of a specialist.

Other important information (provided by the modified enterprise logistics model) is to highlight the material flow intensity using the Sankey Diagram (Figure 11.).

\section{CONCLUSIONS}

The problem of creating simulation models for business logistics is determined high demanding to master a whole range of different skills and knowledge. Their implementation is conditional on long-term practice and experience. Also, some skill in controlling the simulation program is needed. Thus, the fact so significantly impedes its further expansion and exploitation.

Today, the efforts of producers (but also of individual enterprises) are aimed at finding ways to make it more efficient and maximized. One of these options is the presently presented approach, which was used to create a simulation model of the system of supplying production using logistic trains. Its application in the initial phase requires disposal to know the necessary information and the expected results. The result is the creation of modular simulation blocks that can be used to create a simple model of a particular enterprise logistics process and subsequently modify this model. Managing such work is possible based on short-term training from building block makers. Thus, the simulation model becomes an instrument for everyday logistics practice.

\section{Acknowledgements}

This contribution is the result of the projects VEGA 1/0403/18, VEGA 1/0063/16, VEGA 1/0708/16, KEGA 018TUKE-4/2016.

\section{REFERENCES}

1. Strohmandl J. Use of simulation to reduction of faulty products. UPB Sci. Bull. Ser. D Mech. Eng., 76, 2014, 223-230.

2. Klozíková J. and Dočkalíková I. Decision Support in Rating of the Level of Corporate Governance Using the WINGS Method. In: 11 th European Conference on Management, Leadership and Governance, ECMLG 2015. 569 - 579, 2015.

3. Nedeliakova E., Sekulova J., Nedeliak I. and Abramovic B. Application of raymond fisk model in researchof service quality. Komunikacie 2 (18), 2016, 11-14.

4. Fabianová J., Kačmáry P., Molnár V. and Michalik P. Using a Software Tool in Forecasting: a Case Study of Sales Forecasting Taking into Account Data Uncertainty. Open Eng., 6 (1), 2016, 270-279.

5. Bergmann S., Feldkamp N. and Strassburger S. Journal of Simulation 11, 2017, 38-50.

6. Chankov S.M., Malloy G. and Bendul J. The Influence of Manufacturing System Characteristics on the Emergence of Logistics Synchronization: A Simulation Study. In: 5th International Conference LDIC, 2016 Bremen, Germany, Springer International Publishing, pp. 29-40, 2016.

7. Tao F., Cheng J., Cheng Y., Gu S., Zheng T. and Yang H. Robotics and Computer-Integrated Manufacturing 45, 2017, 34-46.

8. B. Costa, L.S. Dias, J.A. Oliveira, and G. Pereira: In: IEMC-Europe 2008 - 2008 IEEE International Engineering Management Conference, Europe: Managing Engineering, Technology and Innovation for Growth, Estori, 2008.

9. Dias L.S., Vik P., Oliveira J.A. and Pereira G. Simulation in the design of an internal logistic system-Milk run delivering with Kanban control. In: 10th International Industrial Simulation Conference 2012, ISC 2012, EUROSIS, Brno, 159-66, 2012.

10. Ficzere P., Ultmann Z. and Torok A. Time-space analysis of transport system using different mapping methods. Transport 3 (29), 2014, 278-284. 
11. Bartošíková R., Bilíková J., Strohmandl J., Šefčík V. and Taraba P. Modelling of decision-making in crisis management. In: 24th International Business Information Management Association Conference - Crafting Global Competitive Economies: 2020 Vision Strategic Planning and Smart Implementation. 2014, 1479 -1483.

12. Molnár V. and Pačutová K. Assessing the possibilities of reducing the transport company costs. In: 3rd International Conference on Traffic and Transport Engineering, ICTTE 2016. 570-575, 2016.

13. Molnár V. Integrated transport system - the main mean of transport for employees to US Steel Kosice. In: Carpathian Logistics Congress, CLC 2013. 561-566, 2013.

14. Mantič M., Kul'ka J., Krajňák J., Kopas M. and Schneider M. Influence of selected digitization methods on final accuracy of 3D model. In: Majerník, M., Daneshjo, N., and Bosák, M. (eds.) Production Management and Engineering Sciences. pp. 475-480. CRC Press Taylor and Francis Group A Balkema Book, 2016.

15. Debski H., Koszalka G., Ferdynus M. Application of FEM in the analysis of the structure of a trailer supporting frame with variable operation parameters. Eksploatacja i Niezawodnosc - Maintenance and Reliability, 14, 2012, 107-113.

16. Jachowicz T., Sikora R.: Methods of forecasting of the changes of polymeric products properties. Polimery, 2006, 3 (51), 11-18.

17. Tow train logistics solution. Jungheinrich Official Website (http://www.jungheinrich.co.za/company/ events/ifoy-award/ifoy-award-2015/tow-train-logistics-solution/) 
